\title{
Uterine Myoma Symptoms \& Quality of Life
}

\author{
S Nafees Bano*, Jafri MA, Qamar A Kazmi, Wajeeha Begum and ZA Ansari \\ Govt Unani Medical College, India
}

Submission: March 17, 2017 ; Published: April 19, 2017

*Corresponding author: S Nafees Bano, Principal, HSZH, Govt. Unani Medical College, Bhopal, India, Email: snafeesbano@gmail.com

\section{Introduction}

Uterine Myoma or leiomyomas are benign tumors of the uterine muscle and the leading cause of hysterectomy [1]. These are clinically detectable in $25 \%$ to $80 \%$ of women in communitybased studies; thus many women have the disease without receiving any treatment [2]. Little is known about the clinical burden of symptomatic fibroid disease or about the decisionmaking process regarding fibroid therapies $[3,4]$. Uterine myoma is the most prevalent benign gynecological tumor [5]. Treatment of this condition has undergone a significant transformation in recent years [6].

It is known that Uterine Myoma causes abnormal uterine bleeding and pelvic pain as main symptoms, impairing women's health related quality of life. However, this last parameter was the object of fewer researches [7]. Various studies have been done to assess the quality of life of patients diagnosed with Uterine Myoma with the use of the only validated measure for fibroid-specific quality of life (UFS-QOL) [8].

The 2011 evidence review on fibroids conducted by the United States' Agency for Healthcare Research and Quality (AHRQ) provided a comprehensive assessment of multiple areas where additional research regarding uterine fibroids is needed [9]. The AHRQ report included as prioritized research questions assessing the "burden of disease" and how "acquisition and processing of available information" allow patients and providers to "identify and choose strategies for fibroid management [10]."

Qualitative studies are important to explore women's feelings about the impact of Uterine Myoma in their lives, the barriers or problems related to pharmacological treatment of Uterine Myoma and to understand their motivations for requesting clinical and/or surgical treatment.

Finally, understanding the perspective of disease from the patient's point of view is seen as increasingly important to optimize health. For uterine fibroids, obtaining this information is very timely given that uterine fibroids are one of the three high-impact research topics announced by the Patient Centered Outcomes Research Institute for 2013 [10].

Women discussed the impact of Uterine Myoma and discussion categories were built, leading to four recognizable major themes, which were: knowledge (beliefs and attitudes) towards UL; fear, unfairness and discouragement; changes in social and professional activities due to bleeding and pelvic pain; and medications for Uterine Myoma [11].

\section{Beliefs and Attitudes Towards Uterine Myoma}

The study showed that participants were concerned that uterine myoma could develop into cancer. Their fear of such an outcome was a motivational factor for seeking clinical and/or surgical assistance, and was obvious from their facial expressions as they discussed the disease. The misconception of uterine myoma as a preneoplastic disease of uterine cancer was a justification to undergo hysterectomy. While several participants had relatives with gynecological malignant neoplasms, others also reported acquiring this information from family members, their partner, or acquaintances, rather than directly from a woman who had experienced this type of cancer [11].

Another group of participants reported having little information about leiomyoma. Some of these women were dissatisfied with their lack of knowledge about the disease and sought out information about it. Physicians and media (internet and television) were their main sources of information. The discussion indicated that the women believed their physicians were responsible for providing them with knowledge [11].

\section{Fear, Unfairness and Discouragement}

Women referred that bleeding and pelvic pain caused a huge sensation of fear, especially because of the unpredictability of these symptoms. Most patients had already tried pharmacological treatment and experienced therapeutic failures, which made them feel discouraged; they felt they did not have enough strength to keep on trying clinical treatment. Unfairness was another feeling reported by women; they could not understand how they used medications correctly and they did not work [11].

Changes in Social and Professional Activities Due to Bleeding and Pelvic Pain

The participants reported that bleeding and pelvic pain limited their domestic and social activities. Some women reported going to hospitals after many episodes of uterine 
bleeding and pelvic pain. Professional activity was also impaired by symptoms. Many women used their symptoms to justify their decision to undergo hysterectomy [11].

\section{Adverse Effects Using Medications}

Most medication-related complaints were associated with the use of hormonal therapies, which had a negative impact on the patients' lives. Such medication was easily recognized by these women due to its subcutaneous route of administration. Despite its beneficial effects on uterine bleeding and pelvic pain, in general, most women reported that their quality of life considerably worsened after using this drug; they reported unpleasant vasomotor and urogenital symptoms usually associated with hypoestrogenism. Add-back therapy was offered to these patients; however, only few patients could actually use the medication due to financial limitations [11].

The study had found that women with uterine myoma had a negative impact in their quality of life when the symptoms had started, and treatment failure with medications triggered diverse negative sensations and modified coping strategies towards this disease [11].

The wrongful association of uterine myoma with cancer was widely reported by patients during the interviews. However, we could not find any uterine myoma study discussing the effects of cancerophobia. In fact, the risk for leiomyosarcoma is extremely low, and this tumor is often incidentally detected in hysterectomy specimens [12]. Moreover, lack of knowledge of the actual physiopathology of the disease may influence the treatment decision-making process; therefore, it is worrisome that women do not have adequate knowledge to make the right decision [11].

These findings likely have cost implications for both individuals and the healthcare system and the existing literature on costs of uterine fibroids is limited. For example, the cost of both missed work days and limitations on productivity and career advancement need to be studied to understand the true costs of uterine fibroids [10].

Last, but not least, studying treatments for uterine fibroids is critical. Hysterectomy has been the primary therapeutic tool in the gynecologic armamentarium for uterine fibroids for decades. However, the strong findings related to reproductive concerns in the women of all ages suggests that educating this particular group about alternative to hysterectomy is especially important.

Understanding and addressing the needs of the severely affected women with uterine fibroids are key goals for healthcare providers and researchers [10]. More research needs to be done regarding uterine-sparing alternatives to hysterectomy. A variety of effective techniques can be used based on the woman's symptoms, her fibroid burden, and her reproductive plans [4].

\section{Conclusion}

Uterine myoma are a major source of morbidity for reproductive-age women. Uterine myoma symptoms impair women's lives significantly. It was shown during interviews that uterine bleeding lead to negative sensations, such as fear and unfairness. These feelings impair the social and health world of women who suffer with this disease. Individual differences in disease representation may correspond to differences in women's relative stress levels. This indicates the importance of identifying other medical and psychological concerns of women diagnosed with this disease.

Health professionals need to comprehend individual and cultural differences contributing to a woman's understanding of her condition. Quality of information is important to the patient and to all who surround her [13]. Treatment of this pathology is multidisciplinary (involving psychology, nursing, and many other fields). The doctor-patient relationship, in addition to other motivational factors, should be considered during the patient's decision-making process. Moreover, verbal and nonverbal communications from the patients should be considered.

\section{Acknowledgement}

This study related to Uterine Myoma and effect of Unani Formulation was done at NIUM, Bangalore from 2005 to 2007. The Uterine Fibroid symptoms and the effect on Quality of life was also studied with the only validated UFS-QOL questionnaire [8]. There was significant improvement in the QOL after the treatment. I am thankful to the Director \& the Ministry of AYUSH for the funding of the research work.

\section{References}

1. Carlson KJ, Nichols DH, Schiff I (1993) Indications for hysterectomy. N Engl J Med 328: 856-860.

2. Baird DD, Dunson DB, Hill MC, Cousins D, Schectman JM (2003) High cumulative incidence of uterine leiomyoma in black and white women: Ultrasound evidence. Am J Obstet Gynecol 188(1): 100-107.

3. Walker CL, Stewart EA (2005) Uterine fibroids: The elephant in the room. Science 308: 1589-1592.

4. Laughlin SK, Stewart EA (2011) Uterine leiomyomas: Individualizing the approach to a heterogeneous condition. Obstet Gynecol 117(2 Pt 1): $396-403$

5. Stewart E (2001) Uterine Fibroids. The Lancet 357: 293-288.

6. Munro M (2007) Management of heavy menstrual bleeding: is hysterectomy the radical mastectomy of gynecology? Clin Obstet \& Gynecol 50(2): 324-353.

7. Williams V, Jones G, Muskopf J, Spalding J, DuChane J (2006) Uterine fibroids: a review of health-related quality of life assessment. J Womens Health 15(7): 818-829.

8. Spies JB, Coyne K, Guaou N, Boyle D, Skyrnarz-Murphy K,et al. (2002) The UFS-QOL, a new disease-specific symptom and health-related quality of life questionnaire for leiomyomata. Obstet Gynecol 99(2): 290-300.

9. Gliklich RE, Leavy MB, Velentgas P, Campion DM, Mohr P, et al. (2011) Identification of future needs in the comparative management of uterine fibroid disease. A report on the Priority-Setting Process, Preliminary Data Analysis, and Research Plan. Agency for Healthcare Research and Quality.

10. Elizabeth A, Stewart MD, Wanda K, Nicholson MD, Linda Bradley, et al (2013) The Burden of Uterine Fibroids for African-American Women: 
Results of a National Survey. J Womens Health (Larchmt) 22(10): 807 816

11. Brito LG, Panobianco MS, Sabino-de-Freitas MM, Barbosa Hde F, de Azevedo GD, et al. (2014) Uterine leiomyoma: understanding the impact of symptoms on womens' lives. Reprod Health 11(1): 10.

12. Leung F, Terzibachian J, Gay C, Chung Fat B, Aouar Z, et al. (2009) Hysterectomies performed for presumed leiomyomas: should the fear of leiomyosarcoma make us apprehend no laparotomic surgical routes? Gynécologie Obstétrique \& Fertilité 37: 1014

13. Kai J, Beavan J, Faull C (2011) Challenges of mediated communication disclosure and patient autonomy in cross-cultural cancer care. $\mathrm{Br}$ J Cancer 105(7): 918-924.
This work is licensed under Creative

Commons Attribution 4.0 Licens

DOI: $10.19080 / J G W H .2017 .04 .555630$
Your next submission with Juniper Publishers will reach you the below assets

- Quality Editorial service

- Swift Peer Review

- Reprints availability

- E-prints Service

- Manuscript Podcast for convenient understanding

- Global attainment for your research

- Manuscript accessibility in different formats

( Pdf, E-pub, Full Text, Audio)

- Unceasing customer service

Track the below URL for one-step submission https://juniperpublishers.com/online-submission.php 